International Journal of Applied Earth Observation and Geoinformation,

Volume 74, February 2019, Pages 222-230

DOI:10.1016/j.jag.2018.09.011

\title{
A method for monthly mapping of wet and dry snow using Sentinel-1 and MODIS: application to a Himalayan river basin
}

\author{
B. Snapir ${ }^{\mathrm{a}}$, A. Momblanch ${ }^{\mathrm{a}}$, S.K. Jain ${ }^{\mathrm{b}}$, T.W. Waine ${ }^{\mathrm{a}}$, I.P. Holman ${ }^{\mathrm{a}, *}$ \\ ${ }^{a}$ Cranfield University, Cranfield, Bedfordshire, MK43 OAL, UK \\ ${ }^{b}$ Water Resources Systems Division, National Institute of Hydrology, Roorkee, India
}

\begin{abstract}
Satellite Remote Sensing, with both optical and SAR instruments, can provide distributed observations of snow cover over extended and inaccessible areas. Both instruments are complementary, but there have been limited attempts at combining their measurements. We describe a novel approach to produce monthly maps of dry and wet snow areas through application of data fusion techniques to MODIS fractional snow cover and Sentinel-1 wet snow mask, facilitated by Google Earth Engine. The method is demonstrated in a $55,000 \mathrm{~km}^{2}$ river basin in the Indian Himalayan region over a period of $\sim 2.5$ years, although it can be applied to any areas of the world where Sentinel-1 data are routinely available. The typical underestimation of wet snow area by SAR is corrected using a digital elevation model to estimate the average melting altitude. We also present an empirical model to derive the fractional cover of wet snow from Sentinel-1. Finally, we demonstrate that Sentinel-1 effectively complements MODIS as it highlights a snowmelt phase which occurs with a decrease in snow depth but no/little decrease in snowpack area. Further developments are now needed to incorporate these high resolution observations of snow areas as inputs to hydrological models for better runoff analysis and improved management of water resources and flood risk.
\end{abstract}

Keywords: snow, MODIS, Sentinel-1, Google Earth Engine, Himalayas

\section{Introduction}

Snow is a key environmental indicator affecting both local and global climate, and is a precious source of freshwater as about one-sixth of the world's

\footnotetext{
*Corresponding author, i.holman@cranfield.ac.uk

Email addresses: b.j.snapir@cranfield.ac.uk (B. Snapir), andrea.momblanch-benavent@cranfield.ac.uk (A. Momblanch), sanjay.nih@gmail.com (S.K. Jain), t.w.waine@cranfield.ac.uk (T.W. Waine)
} 
population relies on rivers fed by the melting of seasonal snow and glaciers [1].

5 The Himalayas are of particular importance as they hold the third largest deposit of ice and snow in the world, after the polar regions, and are the source of the major rivers of South Asia 2. The seasonal snow cover area (SCA) is commonly used as a proxy for estimating and forecasting water runoff from snow melt [3, 4]. Previous studies have shown that satellite Remote Sensing (RS) with

10 both optical and Synthetic Aperture Radar (SAR) instruments can inform the understanding of the spatial and temporal variability of SCA [5]. Optical instruments like the Moderate Resolution Imaging Spectroradiometer (MODIS) and the Advanced Very High Resolution Radiometer (AVHRR) provide mature measurements of fractional SCA via the Normalized-Difference Snow Index (NDSI)

15 6. In particular, AVHRR and MODIS offer long time series (from 1978 to today) of SCA measurements which are desirable to monitor long-term hydrological processes [7. These measurements refer to the total SCA but can not discriminate wet and dry snow. Dry snow is only composed of ice particles and air, while wet snow has liquid water as a third component [8]. In contrast, SAR

20 can identify areas of wet snow but is unable to detect dry snow [9, 10, 11, 12. Wet snow is typically identified using change detection applied to the backscatter ratio between an image with wet snow and a reference image with only dry snow or no snow. A constant threshold of $-2 \mathrm{~dB}$ or $-3 \mathrm{~dB}$ is often used to generate a wet snow mask 9, 11, 13, 14. Soft thresholds, as a function of the backscatter

25 ratio, have been used to derive the probability of wet snow [15, 16, 17]. [18] also suggested a method to retrieve the fractional cover of wet snow, $F_{w}$, using the ratio,

$$
F_{w}=\frac{\sigma^{0}-\sigma_{g}^{0}}{\sigma_{w}^{0}-\sigma_{g}^{0}}
$$

where $\sigma^{0}$ is the observed backscattering coefficient for an image during the melting period, $\sigma_{g}^{0}$ is the backscattering coefficient of snow-free ground, and

sо $\quad \sigma_{w}^{0}$ is the wet snow backscattering coefficient at the beginning of the melting season. These studies often use optical measurements of SCA to validate the SAR detection of wet snow (with the underlying assumption that all the SCA is wet snow) and have reported that SAR tends to underestimate the SCA near the snow line.

35 Snowmelt does not necessarily translate into a decrease in total SCA, especially in areas with deep snowpack where melting may result only in a decrease in snow depth. While this melting phase cannot be detected by the MODIS measurements of total SCA alone, it may be detected by the SAR measurements of wet snow. Therefore, combining optical and SAR measurements could improve the monitoring of snowmelt for more accurate runoff estimation and watershed management especially in sparsely-monitored and inaccessible areas [17. However, so far, the SAR measurements have mainly been used in cloudy conditions to complement the MODIS measurements [19, 20, 21]. Only [17] overlaid wet-snow data from Radarsat-2 and Sentinel-1 over an SCA map from 45 MODIS, so as to derived maps of both wet and dry SCAs for each SAR acqui- 
sition date. Yet their study area was limited to a relatively small river basin $\left(14,000 \mathrm{~km}^{2}\right)$ which could be covered by a single RADARSAT-2 ScanSAR Wide image. For larger areas, a strategy is needed to deal with the different imaging dates of multiple SAR swaths. In this paper, we present a strategy based on the fusion of monthly MODIS and Sentinel-1 image composites which allows generating high-resolution monthly maps of wet and dry SCAs over large areas. Our approach also corrects the typical underestimation of the wet SCA by Sentinel-1 using the MODIS measurements and a Digital Elevation Model (DEM). The implementation is facilitated by Google Earth Engine (GEE), a

55 cloud computing platform which provides global-scale analysis capability and a multi-petabyte catalogue of satellite imagery including images from MODIS and Sentinel-1 22. The method is applied to a large Himalayan river basin, but could be extended to any area of the world where Sentinel-1 data are routinely available, toward global wet/dry snow maps.

60 The study presented here is part of the project Sustaining Himalayan Water Resources in a Changing Climate (SusHi-Wat), which aims at improving our understanding on how water is stored in, and moves through, a Himalayan river system in northern India.

\section{Materials}

65 2.1. Study area

The study area are the catchments of two large reservoirs in the Indian state of Himachal Pradesh, which have a total catchment area of around $55,000 \mathrm{~km}^{2}$ extending into China. Fig. 1 shows the extent of the whole catchment. The altitude, computed using the DEM from the Shuttle Radar Topography Misto sion (SRTM), ranges from $600 \mathrm{~m}$ above sea level in the west to $6,800 \mathrm{~m}$ in the Himalayan mountains, and the dominant land covers, according to the MODIS land cover product (MCD12Q1), are sparsely vegetated (41\%) and grasslands $(26 \%)$. Rice and wheat are the main cultivated crops and are grown during the wet season (May-October) and during winter respectively [23]. The area 75 is imaged by 21 Sentinel- 1 frames (10 frames from ascending passes, 11 frames from descending passes) and two MODIS tiles (h24v05 and h25v05). The Pong and Bhakra reservoirs are used for hydropower generation and irrigation supply, and are fed by the Beas and Sutlej rivers, respectively. The reservoir inflows are highly seasonal due to the changing importance of snowmelt, with the lowest

so flows in the winter when precipitation occurs mostly as snowfall. Warmer spring temperatures lead to increasing snowmelt and river flows. As the seasonal snowpack becomes depleted over the summer, glacier melt increasingly contributes to runoff and overlaps in time with monsoon rainfall, leading to the highest river discharges in July-August. On average, these rivers receive between 39 and $60 \%$ 85 of their runoff from melting of snow and glaciers [3, 4.

\subsection{SAR measurements - Sentinel-1}

The processing of the images from the Sentinel-1 constellation (Sentinel-1A and Sentinel-1B) was facilitated by GEE which provides a database of analysis- 


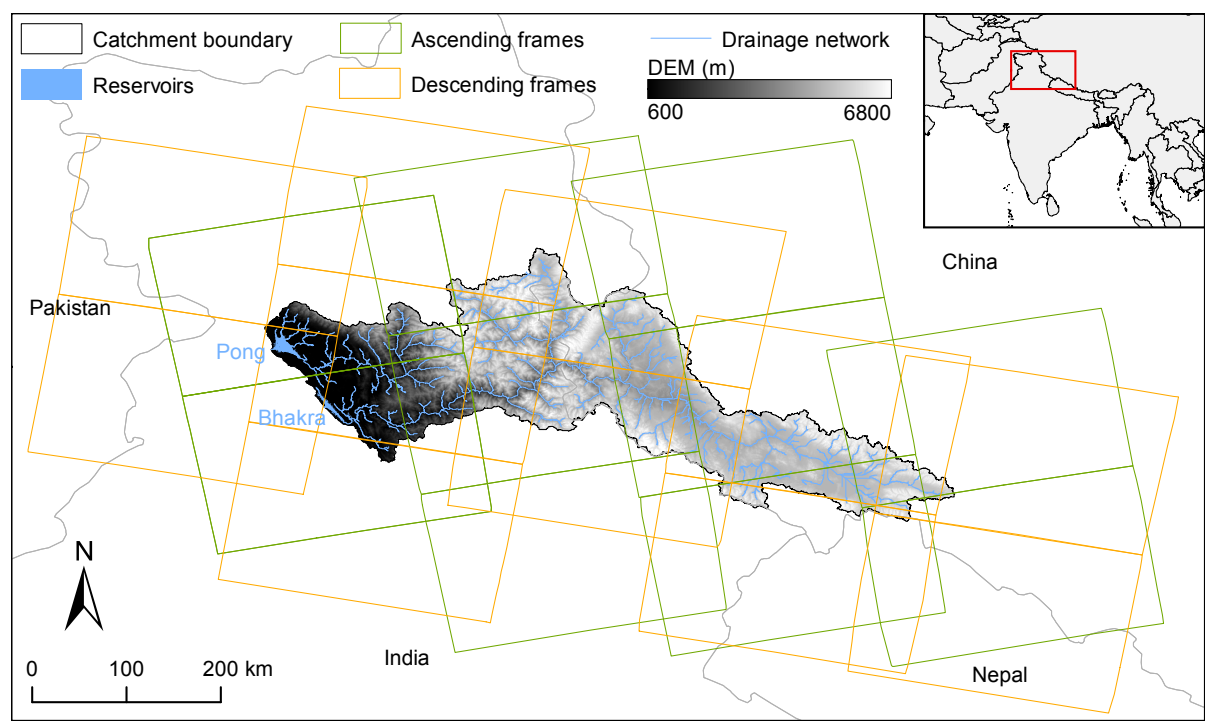

Figure 1: Location and extent of the studied catchment $\left(55,000 \mathrm{~km}^{2}\right)$. The catchment is covered by 21 Sentinel-1 frames - 10 frames from 4 ascending passes (green) and 11 frames from 5 descending passes (orange). The Pong and Bhakra reservoirs receive water runoff from rainfall and snowmelt via the drainage network (blue).

ready Sentinel-1 images. These analysis-ready images were obtained by processing Ground Range Detected (GRD) Sentinel-1 images using the Sentinel-1 Toolbox 24 to generate calibrated and terrain-corrected images. For the study area and the study period, the standard acquisition mode is single polarization with vertical transmission and vertical reception (VV). Fig. 2 shows that when only Sentinel-1A was available, there were on average a total of $25 \mathrm{im}$ ages per month, i.e. each image frame was visited about 1.2 times a month, and this number doubled with the addition of Sentinel-1B. It follows that each point of the catchment is visited from 1 to 8 times per month depending on (i) the overlap between the image frames (Fig 1) and (ii) the acquisition plan of Sentinel-1. June and July 2016 have the lowest numbers of images - 31\% and $10 \%$ of the study area was not imaged in June and July 2016 respectively. While MODIS is an always-on instrument with daily near-global coverage which provides SCA measurements twice a day (MODIS Terra and MODIS Aqua) for the two swaths needed to cover the catchment, Sentinel-1 needs multiple days to image the whole catchment. This is because (i) the higher resolution of Sentinel-1 (20 m) comes with a smaller image swath $(250 \mathrm{~km})$ and (ii) Sentinel-1 only image areas according to its acquisition plan, i.e. the instrument is not always switched on. For example, it took from the $1^{\text {st }}$ May 2015 to the $20^{\text {th }}$ May 2015 (20 days) for Sentinel-1 to image the whole catchment. Therefore, a temporal resolution of one month was deemed appropriate to produce snow maps with full coverage of the catchment (with the exception of June and July 2016). 


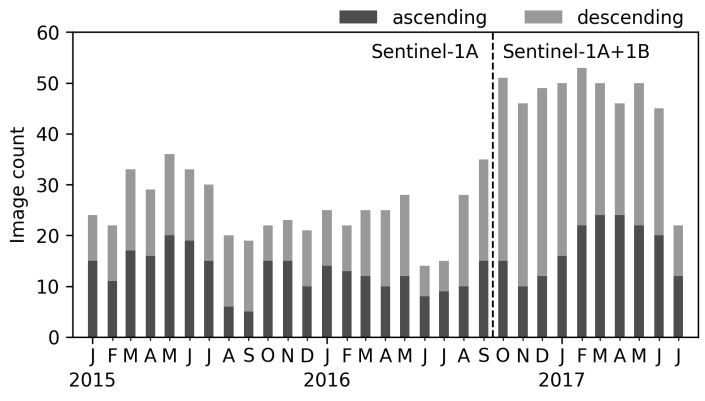

Figure 2: Number of Sentinel-1 images per month (total 1044 images) for the North-East Indian catchment $\left(138,000 \mathrm{~km}^{2}\right)$

The low revisit frequency of Sentinel-1, compared to the daily images from MODIS Terra \& Aqua, also means that Sentinel-1 may not always fully capture the wet SCA of a given month. The local time of image acquisition is also relevant. Sentinel-1 may miss some wet-snow areas because the images are acquired at around 06:30 (descending pass) and 18:30 (ascending pass) local time, compared to 11:00 and 14:00 for MODIS Terra and MODIS Aqua, respectively. We implemented a method, detailed in section 3.2 , to correct area estimates for the associated potential underestimation of wet SCA by Sentinel-1.

\subsection{Optical measurements - MODIS}

The two MODIS instruments, on-board the National Aeronautics and Space Administration's Terra and Aqua satellites, provide daily images of fractional SCA (no distinction between wet and dry snow) at $500 \mathrm{~m}$ resolution (MOD10A1 and MYD10A1 collection 6 products) [25]. The measurement accuracy is about $93 \%$ and varies with the land cover [26]. The product tends to underestimate snow for forested areas where dense canopies may hide the underlying snow pack. This limitation is not critical for our river basin which has only $1 \%$ of forested area. The product may also overestimate snow due to snow/cloud confusion particularly for cloud-shadowed land and thin snow cover. Although methods have been suggested to reduce this overestimation using meteorological measurements from weather stations [27, 28, none was implemented in this study as the required meteorological data were not available. Finally the typical image obstruction by clouds was effectively mitigated by generating monthly cloud-free composites - the daily Terra and Aqua images were combined by 135 averaging the cloud-free pixels. On average, from January 2015 to July 2017, each pixel was imaged without cloud 35 times a month, the worst month being January 2017 with, on average, each pixel imaged without cloud only 20 times. Therefore, the monthly composites are expected to reliably capture the average fractional snow cover of each month. 
(a) Wet snow area detection

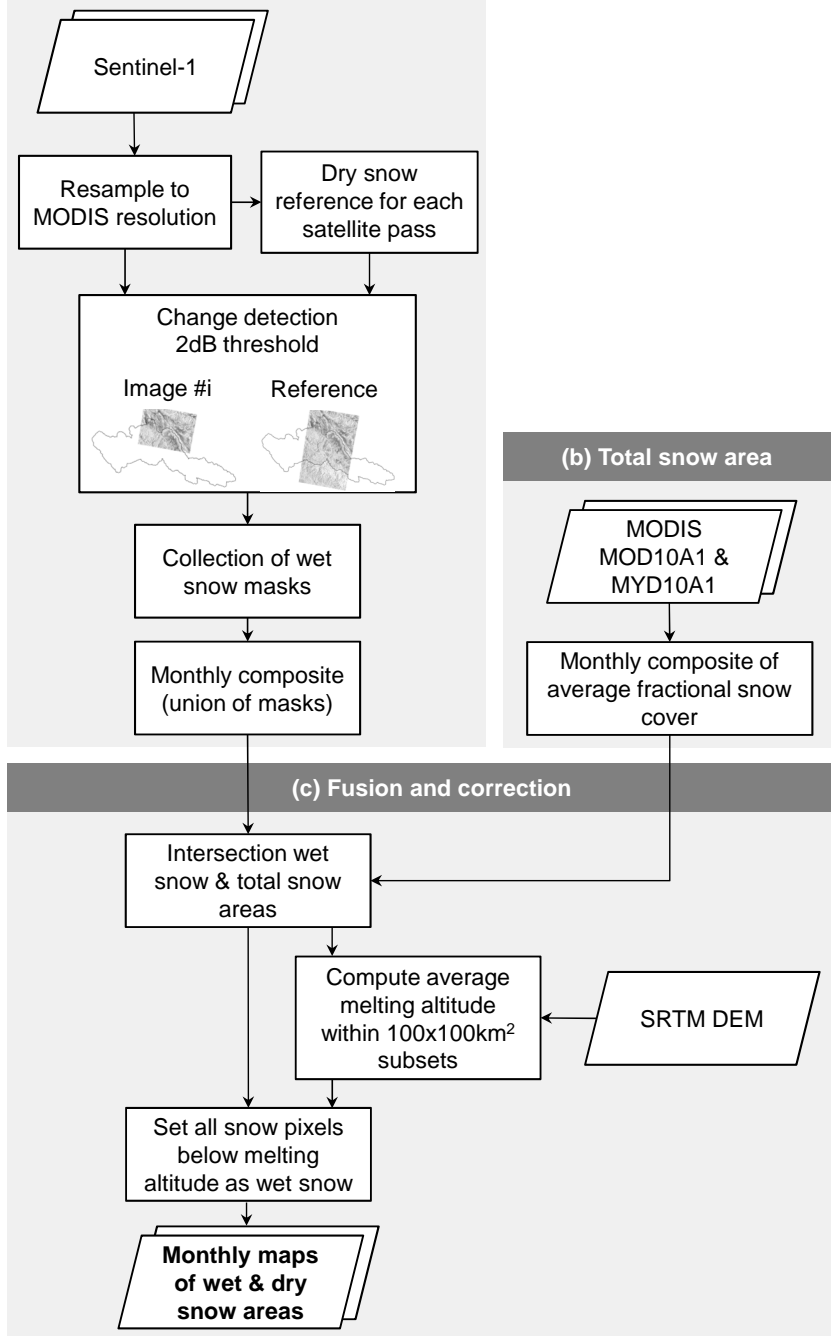

Figure 3: Methodology to produce monthly maps of fractional cover for dry and wet snow. First, (a) monthly masks of wet snow and (b) monthly fractional covers of total snow are created using Sentinel-1 and MODIS, respectively. Then, (c) the wet snow masks and the fractional covers of total snow are combined and corrected to produce the final monthly maps of fractional cover for dry and wet snow. 


\subsection{Wet snow area detection}

The wet snow detector is based on change detection applied to the ratio of backscatter intensity between a given Sentinel-1 image $\left(\sigma^{0}\right)$ and a reference image with dry snow conditions $\left(\sigma_{g}^{0}\right)\left[11\right.$, i.e. the ratio is $\sigma^{0} / \sigma_{g}^{0}$ (or $\sigma^{0}-\sigma_{g}^{0}$ in 145 decibels). First, all the images are resampled to match the $500 \mathrm{~m}$ resolution of MODIS. Resampling was done by computing the mean of all the pixels within a $500 \mathrm{~m}$ window. This resampling step also works as a speckle filter with a $25 \times 25$ pixel averaging window. Because change detection must be made between images from the same satellite pass, we created reference images for each pass 150 covering the study area (4 ascending and 5 descending passes, Fig. 1). The reference images were computed by averaging all images acquired in December and January of each year. This period corresponds to the coldest time of the year, with accumulation of dry snow (MODIS measurements show a systematic increase in total SCA), and where wet snow is unlikely. Images did not need 155 to be coregistered before computing the backscatter ratio, because of the high geolocation accuracy of Sentinel-1 [29] compared to the $500 \mathrm{~m}$ resolution of the analysis. Pixels with a ratio value $\left(\sigma^{0} / \sigma_{g}^{0}\right)$ below the $-2 \mathrm{~dB}$ threshold, selected in accordance with the study from [9] using Sentinel-1 data, were marked as wet snow. The output of this first step is a collection of wet snow masks, one for

\subsection{Fusion of wet snow area (Sentinel-1) and total snow area (MODIS)}

From the collection of wet snow masks (Sentinel-1), we created monthly composites by taking the union of all the masks for a given month, i.e. the maximum extent of wet snow. We then used the monthly wet snow masks 165 with the corresponding monthly fractional snow covers (MODIS) to derive the fractional cover of wet snow. The MODIS snow cover outside the wet snow mask is the fractional cover of dry snow. The wet snow pixels outside the MODIS snow cover are considered false positives (snow-free pixels wrongly detected as wet snow by Sentinel-1) and are marked as no snow. Next, we corrected the fractional snow, but also due to the limited number of Sentinel-1 images per month and the $6 \mathrm{am} / \mathrm{pm}$ acquisition time. For each month, we computed the average melting altitude as the average SRTM altitude of the uncorrected wet snow mask within $100 \times 100 \mathrm{~km}^{2}$ subsets, and set all the dry-snow pixels below 175 the average melting altitude to wet snow pixels. We also removed all the water bodies using the MODIS water mask product (MOD44W).

\subsection{Area estimates: correction for missing Sentinel-1 data}

In the previous section, we described a spatial method to correct the snow maps for the underestimation of wet SCA by Sentinel-1. This correction does 180 not compensate for missing data, i.e. areas not covered by Sentinel-1 such as in June and July 2016. When computing the wet snow area estimates, we assumed 
that the area without Sentinel-1 data had the same proportion of wet snow than the area with available Sentinel-1 data . In practice, the largest correction occurs in June 2016 with $31 \%$ of the study area not covered by Sentinel-1, but it only accounts for $0.12 \%$ of the wet snow area, because the Sentinel-1 images are mostly missing over area of low fractional snow cover.

\section{Quality assessment}

\subsection{Effect of local incidence angle}

In Interferometric Wide swath imaging mode, the incidence angle of Sentinel1901 ranges from $29 \mathrm{deg}$ (near-range) to $46 \mathrm{deg}$ (far range), but the Himalayan topography leads to a wider range of local incidence angles (Fig.4a). Previous studies reported a decrease in the SAR contrast between wet-snow areas and non-wet-snow areas at extreme local incidence angles, i.e. below $20 \mathrm{deg}$ or above $70 \mathrm{deg}$ [9, 30]. This is confirmed by Fig. 4b which shows the angular variations of backscatter ratio for wet and dry snow areas for images acquired in May 2017. This month was selected because it corresponds to a time of the year with established melting conditions and still significant snow-covered areas. Pixels from both ascending and descending images have been aggregated in bins of 5 deg. The analysis is limited to pixels with local incidence angle between $10 \mathrm{deg}$ and 20080 deg because outside this range, the backscatter measurements become unreliable 9. At incidence angle away from $40 \mathrm{deg}$, the backscatter ratio approaches the $-2 \mathrm{~dB}$ threshold, so wet and dry SCAs become less separable. Fig. 5 shows that combining ascending and descending passes only partially alleviates this limitation as, for example, a pixel observed with a $70 \mathrm{deg}$ incidence angle on an ascending pass, tends to be seen with a 10-30 deg incidence angle on the descending pass. The main benefits of combining ascending and descending passes are the increase in temporal resolution and the decrease in shadowed areas.

\subsection{Robustness to different dry snow references}

Fig.6 shows the impact of using a dry snow reference different from the one described in Section3.1. The three curves of area estimates of wet SCA are similar, which suggests that the wet SCA detected by Sentinel-1 is robust against the choice of the dry snow reference used in backscatter ratio. Note that a separate dry snow reference mosaic for 2016 could not be computed, because parts of the study area were not imaged by Sentinel-1 during that period. As expected, the largest differences between the wet snow curves with dry snow reference in 2015 (reference '15 yellow) and dry snow reference in 2017 (reference '17 green) occur during the melting period of 2017 and 2015, respectively, where the time difference between the two references is the largest (2 years). In comparison, the curve with dry snow reference using all the images 220 available in December and January of each year (reference 151617 blue), as implemented in Section 3.1. agrees with the 2015 curve throughout year 2015, and agrees with the 2017 curve throughout year 2017. Combining dry snow images from every available year is therefore demonstrated to provide the most robust dry snow reference for the studied period. 


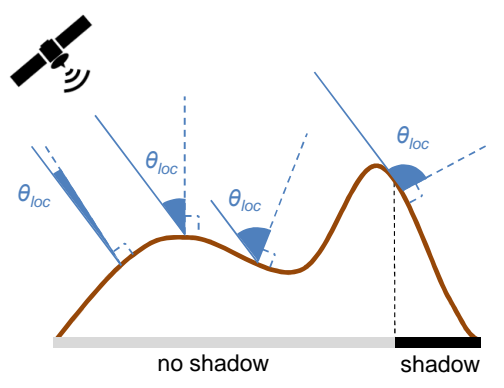

(a)

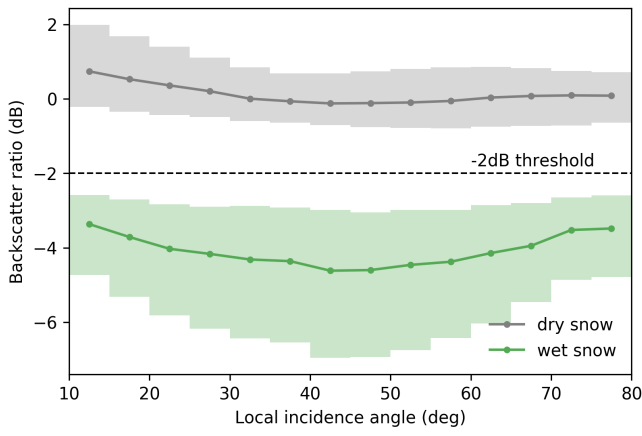

(b)

Figure 4: (a) The local incidence angle $\left(\theta_{l o c}\right)$ is modulated by the topography. (b) Backscatter ratio for Sentinel-1 images in May 2017 resampled at $500 \mathrm{~m}$ resolution, as a function of the local incidence angle for pixels in the wet SCA (green) and pixels in the dry SCA (gray). The middle line is the median and the shaded area corresponds to first and third quartiles. Statistics are computed for pixels from ascending and descending images aggregated in bins of $5 \mathrm{deg}$.

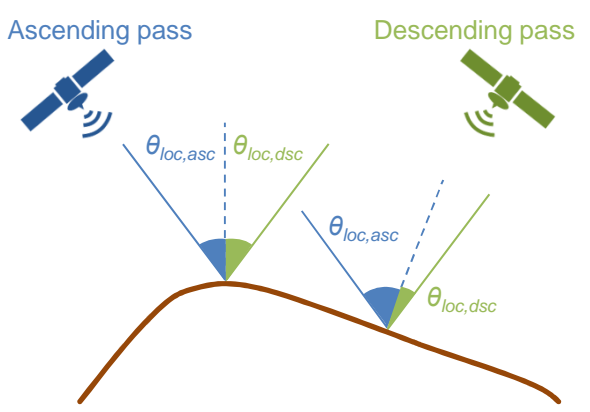

(a)

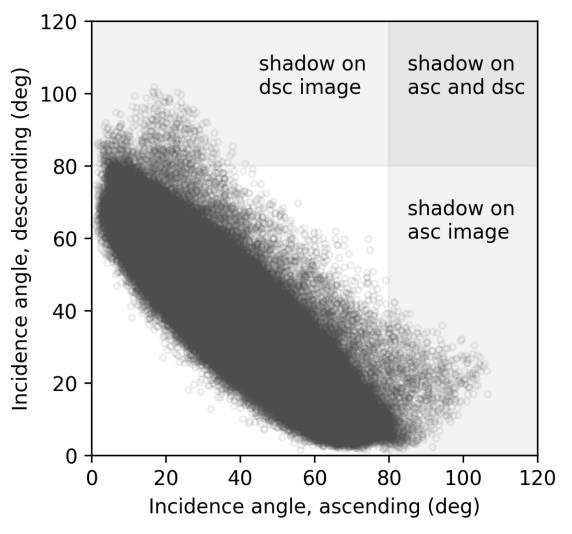

(b)

Figure 5: Comparison between local incidence angle of ascending (asc) and descending (dsc) passes. (a) A pixel which is seen with a large incidence angle on the ascending pass, tends to be seen with a low incidence angle on the descending pass, and vice versa. (b) Local incidence angle of ascending and descending passes. Combining ascending and descending passes effectively removes shadows but only partially mitigate the reduced detection capability of SAR at extreme incidence angles. 


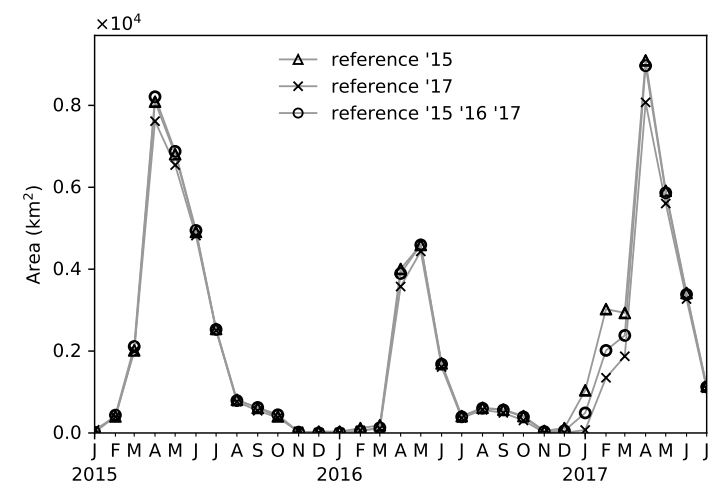

Figure 6: Wet SCA detected by Sentinel-1 for three different dry snow references: Dec 2014 - Jan 2015 (reference '15, yellow), Dec 2016 - Jan 2017 (reference '17, yellow), Dec and Jan of every year (reference '15 '16 '17, blue). Reference '15 '16 '17 is the most robust dry snow reference for the studied period.

\subsection{Effect of low fractional snow cover}

Based on a comparison between snow areas detected by SAR and by optical sensor, previous studies reported that SAR underestimates the snow area, par250

Pixels wrongly detected by Sentinel-1 as wet snow, can be quantified by computing the wet snow pixels detected outside the MODIS snow mask. Fig7 shows that false positives are only a small fraction of the total catchment area ( $0.9 \%$ at worst; black curve). This is thanks to the large number of images used to compute the dry-snow reference and the significant speckle averaging during the resampling to $500 \mathrm{~m}$ resolution. According to the MODIS land cover data, the overall increase in false positives during March-October (black curve) occurs in grasslands and sparsely-vegetated areas. Surface scattering from the soil may be progressively replaced by volume scattering in the vegetation as it grows during summer. This volume scattering has a depolarisation effect which may result in a decrease in co-polarised backscatter (here VV) 31 leading to the false positives. Dual-polarisation images $(\mathrm{VV}+\mathrm{VH})$ would be needed to further investigate this source of false positives. During November-January, the few pixels detected as wet snow by Sentinel-1 are mainly false positives (blue curve). Further inspection revealed that these false positives occur around the boundaries of the two reservoirs (Pong and Bhakra). The surface area of these reservoirs varies over time because of the monsoon, snow/glacier melt, and reservoir operation. As a result, the reservoirs sometimes extend outside the MODIS water mask product used to remove water bodies, leading to false positives. All the false positives are automatically discarded when generating the monthly maps as they are outside the MODIS snow mask.

ticularly near the snow line where the SAR pixel is a mixture of wet-snow and non-wet-snow areas (no snow or dry snow) [11, 21, 32]. This is verified by Fig. 8 


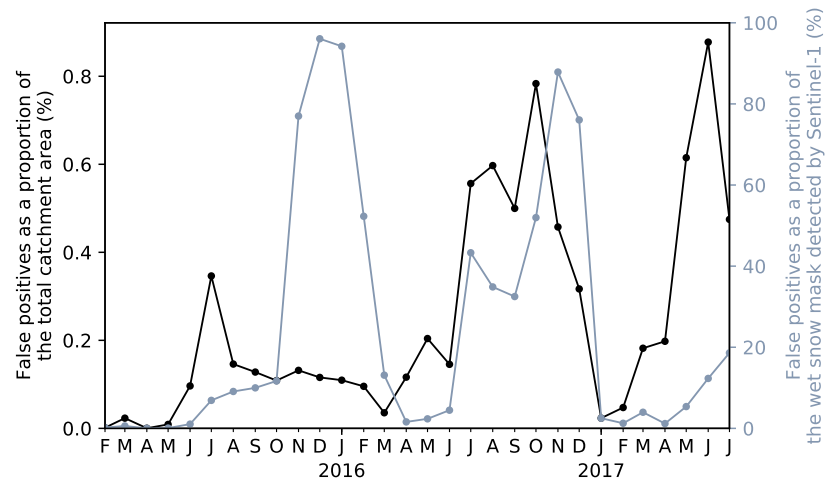

Figure 7: False positives as a proportion of (i) the total catchment area (black) and the wet snow mask detected by Sentinel-1 (blue). False positives are the pixels detected as wet snow by Sentinel-1, but outside the MODIS snow mask, so marked as no snow in the final monthly snow maps.

which shows that the backscatter ratio for wet snow (green line) approaches the $-2 \mathrm{~dB}$ threshold for low fractional snow cover, i.e. misclassification is more likely. In comparison, snow fraction has little effect on backscatter ratio for the dry snow area (black line), confirming that dry snow is mainly transparent to C-band SAR. [18 took advantage of this loss in contrast to estimate the fractional snow cover directly from the SAR images. Their approach (Eq.11) relies on a linear relationship between fractional snow cover $\left(F_{w}\right)$ and the backscatter difference $\left(\sigma^{0}-\sigma_{g}^{0}\right)$ with a slope given by $1 /\left(\sigma_{w}^{0}-\sigma_{g}^{0}\right)$. Instead, our results 260 suggest that an exponential model $\left(F_{w}=-8.17 e^{-6} \exp \left(2.99\left(\sigma^{0}-\sigma_{g}^{0}\right)\right)-2.48\right)$ may be a better approximation.

The reduced detection capability for low snow fraction is clear on Fig.9. which shows a map of wet and dry SCAs for May 2017. The dry SCA is divided into two subsets, the area above the average melting altitude (green) and the area below the average melting altitude (red). The overall melting altitude across the river basin (average of the melting altitudes computed for the $100 \mathrm{~km}$ subsets) is $4635 \mathrm{~m}$ with a standard deviation of $1523 \mathrm{~m}$. The dry SCA below the melting altitude is not detected as wet snow because the average fractional snow cover for this area is only $5 \%$. It is also possible that part of the snow melted 270 before the first Sentinel-1 sampled the area on that month. Either way, the blue area on Fig.9 is wrongly detected as dry snow. As explained in section 3.2, this is corrected by setting all the dry snow pixels below the melting altitude (red area) as wet snow pixels. This correction is not negligible, as for May 2017 it increases the wet SCA by $18 \%$. In the next section looking at time series of 275 SCAs, this correction is applied to each month of the melting period (AprilAugust, see Fig. 6). Applying the correction outside the melting period results in large overestimation of the wet SCA. This is because outside the melting period, small patches of wet snow are detected by Sentinel-1, but these cannot be used to compute a meaningful melting altitude. 


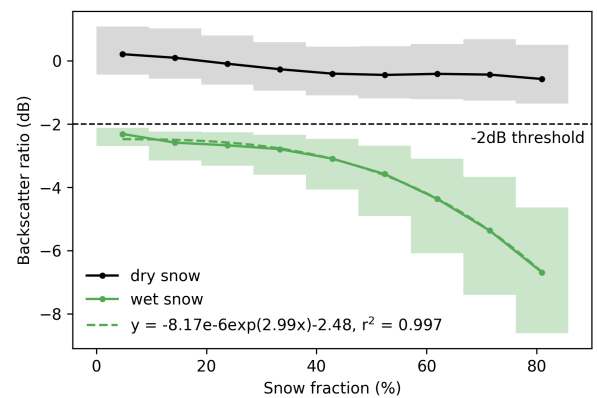

Figure 8: Backscatter ratio for Sentinel-1 images in May 2017 resampled at $500 \mathrm{~m}$ resolution, as a function of the snow fraction measured by MODIS. The data are aggregated in bands of $5 \mathrm{deg}$. The middle line is the median and the shaded area corresponds to first and third quartiles. The model is fitted to the median data points.

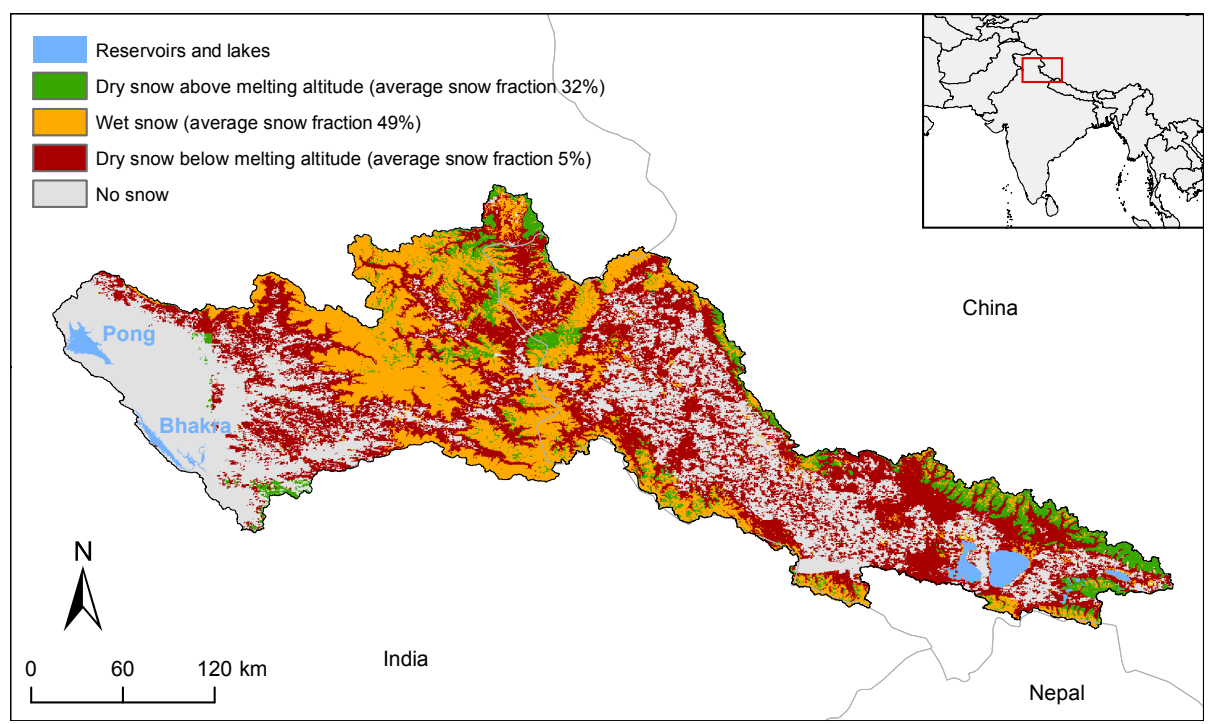

Figure 9: Map of the snow cover area for May 2017. Orange is the wet SCA detected by Sentinel-1. Green and red are the dry SCAs which are above and below the average melting altitude. The correction step sets red area as wet snow. 


\subsection{Snow area estimates}

Fig.10a shows time series of area estimates of dry and wet snow for the whole catchment. The total SCA (wet+dry snow; blue line) reflects significant annual variability - the total snow area in March 2015 is twice that in March 2016. It also shows variations in the timing and extent of the accumulation period the accumulation period in winter 2016-17 started later (December 2016) than the accumulation period in winter 2015-16 (September 2015). This confirms that December-January is the most suitable period to generate the dry snow reference. Fig.10a also shows two estimates of the wet SCA - the wet SCA as detected by Sentinel-1 (dashed orange line) and the wet SCA after corrections (continuous orange line) for (i) undetected wet snow below the melting altitude and (ii) missing Sentinel-1 data. While correction (ii) is negligible even for June and July 2016, correction (i) increases significantly the wet SCA estimate.

Fig. 10b highlights that, while the time series of total SCA informs on the loss of snowpack area due to melting, it does not capture the snowmelt generated through a loss of snow-depth where snow remains at the end of the month. This is apparent in March 2015 and 2017 where there is a large wet snow area (demonstrating melting) but little decrease in total snow area (occurring instead on the following month). This demonstrates that the combined use of total (optical) and wet (SAR) SCA enables a better understanding of the spatiotemporal dynamics of the melting process.

\section{Discussion}

\subsection{Estimation of the fractional cover of wet snow}

Our method relies on MODIS fractional snow cover to convert the wet snow mask obtained with Sentinel-1 into a fractional cover of wet snow. Fig. 8 8 suggests that the fractional cover of wet snow could be directly estimated with Sentinel-1 by applying an exponential model to the backscatter difference $\sigma_{i}^{0}-\sigma_{g}^{0}$ (using the notation of Eq.11). However, a priori, the numerical expression of our model is only valid for the studied catchment and for Sentinel-1 images resampled to $500 \mathrm{~m}$ resolution images. Consequently, further analysis would be needed to assess the validity of the model at finer resolution, and take advantage of the high resolution of Sentinel-1. In terms of model calibration, the linear approach from [18] has the advantage of relying only on SAR images, without the need for the MODIS fractional snow cover. The slope of their linear model is given by $1 /\left(\sigma_{w}^{0}-\sigma_{g}^{0}\right)$, so the model adapts to variations in land covers. This is particularly attractive in regions with forested areas (not present in our catchment) which have been reported to limit the backscatter contrast between wet snow and dry snow (contrast as low as $-1 \mathrm{~dB}[17]$ ). A more detailed analysis of the two methods, over an area with various vegetation covers, would be needed to fully understand their advantages and limitations. 


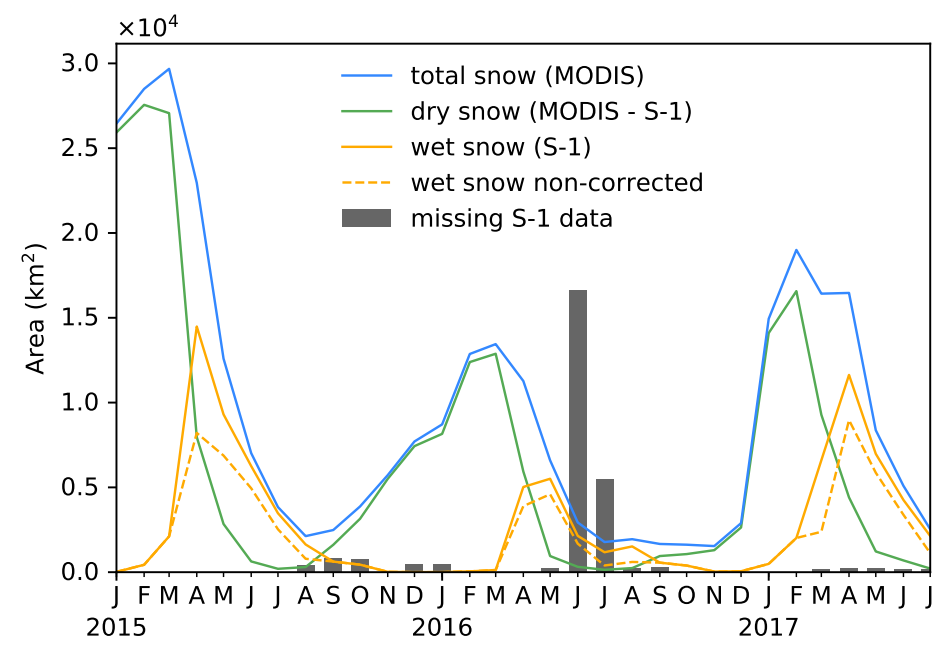

(a)

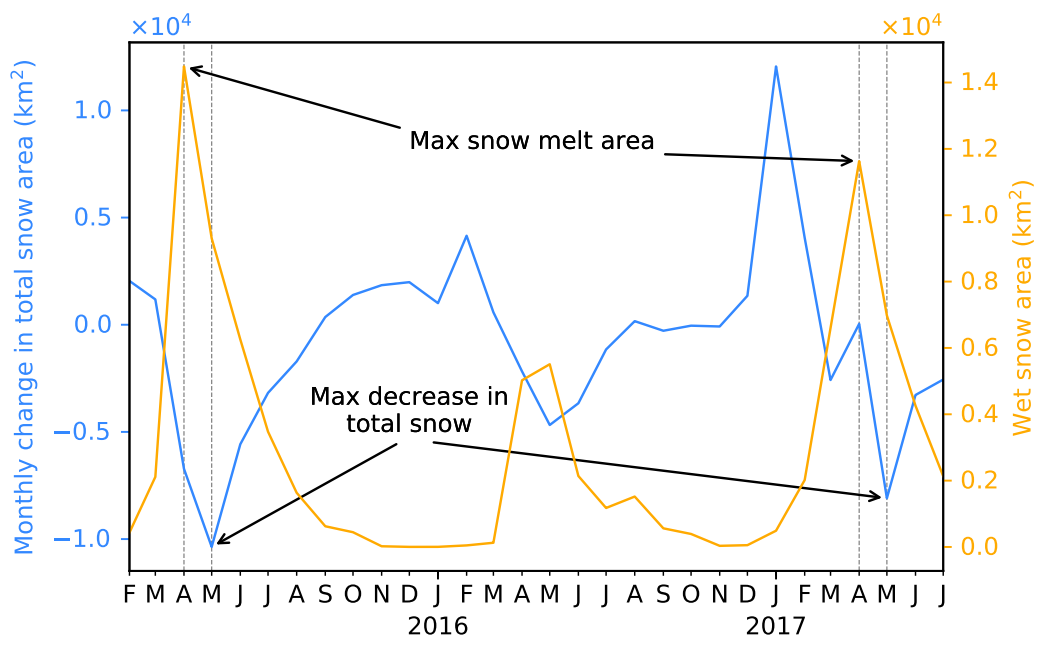

(b)

Figure 10: (a) Time series of monthly SCA estimates for the study area. (b) The wet snow measurements (orange line) in April 2015 and 2017 show that there can be significant snowmelt with no/little decrease in total snow area. The maximum decrease in total snow cover occurs one month after the time of maximum snow melt area. 


\subsection{Selecting the reference image for the SAR change detection}

In theory, images acquired in dry snow or no snow condition can be combined to form the reference mosaic 9 . In practice, the measurements of total snow (Fig. 10a) show that our study area is never completely snow free, so that only images acquired during the accumulation period are reference candidates. For long term monitoring of wet SCA (for example over 15 years), using reference images close to the analysis date may be more suitable than combining all images available for the whole study period as we did for this study (spanning only 2.5 years). For example, this would limit erroneous detection due to long term changes in land uses and land covers. The reference images used for a given analysis year could be dynamically selected from knowledge of the accumulation period with the MODIS measurements of total snow.

\subsection{Impact of Sentinel-1 acquisition time and revisit frequency}

The Sentinel-1 satellites, like most spaceborne SAR, are on a dawn-dusk orbit and cross the equator around 06:00 (descending pass) and 18:00 (ascending pass). This is driven by power requirements of the SAR instrument the dawn-dusk orbit allows the satellites' solar panels to continuously see the Sun. These imaging times are not optimal for monitoring wet snow because of potential refreezing of the snowpack in the early morning and late afternoon which may result in underestimation of snowmelt [11. The effect of the acquisi-

340 tion time could be investigated to some extent by comparing the backscattering coefficient of ascending and descending pairs of images for areas imaged with similar incidence angle (Fig.5b). However, correcting for the underestimation of wet snow may not be straightforward. For example, a correction could be based on temperature measurements from weather stations which would reflect the diurnal variations in snowmelt, but these local ground measurements will not capture spatial heterogeneities in temperature.

The limited revisit frequency of Sentinel-1 may also impact the accuracy of the wet snow area estimates. While the daily MODIS images are likely to provide reliable estimate of the average SCA for each month, the sparser 350 Sentinel-1 images may not always capture accurately the corresponding wetsnow fraction. This is particularly true if the wet SCA varies significantly within a given month. As a result, the wet SCA estimate for March (where the melting season starts but snowmelt may not occur everyday) is likely to be less accurate than that of April (where snowmelt is clearly established). The impact of the limited data availability was certainly more severe when only Sentinel-1A was available. With the addition of Sentinel-1B in October 2015, any location in the river basin was covered at least 5 times per month (6-day revisit frequency) with a maximum of 13 times in areas with overlapping images. One way to assess the uncertainty of wet snow estimate for a given month would be to look at the variation in wet snow mask across the Sentinel-1 images. Small variations would suggest that the wet snow area may be relatively constant throughout the month and that it can be reliably captured even with few Sentinel-1 images. Large variations would signal higher uncertainty on the final wet snow estimate. 


\subsection{Application to hydrological modeling} ral regulation of water resources and flood risk in mountainous catchments in many parts of the world (e.g. Himalayas, Andes, Alps, and Rocky Mountains). They are usually integrated into hydrological models that consider other hydrological processes to produce the different flow components (rainfall-derived ing the most widely used measurements. However, the uncertainty related to sparse weather observations and the difficult distinction between the contributions of the different water sources may lead to significant uncertainty in the imulated river flow 33, 34. This uncertainty can be reduced by improving the understanding of the diverse hydrological processes in play 35, 36.

Data on total SCA are already used as model input in some hydrological models which use temperature index models [37, 38, 39, 40, 41, to calculate snowmelt. They consider that the area of snow cover above a threshold temperature melts at a rate proportional to the temperature or to the temperature and solar radiation, which may oversimplify snowmelt dynamics 42. Input data that characterize the evolution of the wet SCA could improve the accuracy of modelling results by, for example, supporting the definition of seasonal parameters such as melt rates or albedo [43, 34, and for the calibration/validation 385 of the snowmelt processes [44, 45, 46].

One of the inevitable limitations of RS-derived data for hydrological modelling is the limited length of the time series that can be generated. Such data products may not capture the full historical variability of hydrological process behaviour. Nevertheless, this shortcoming will improve as more years of data become available.

\subsection{Towards global wet and dry snow area monitoring}

Our approach could be deployed to larger areas as GEE was designed for planetary scale analysis. With MODIS, cloud-free monthly composites of total snow are certainly achievable for most parts of the world. Our study period 395 corresponded to the operations ramp-up phase of the Sentinel-1 constellation during which single-polarisation (VV) Interferometric Wide (IW) swath was the standard imaging mode. Since early 2017, Sentinel-1 has reached nearly full operational capacity, which means that dual-polarisation (VV+VH) IW swath mode has become the standard imaging mode over mountainous regions such as for e.g. the Himalayas, the Andes, and the Rocky Mountains. [9] showed that the $\mathrm{VH}$ polarisation has better detection capability at extreme incidence angles than the VV polarisation, and suggested a method to fuse the detections from both polarisations. Their approach could be implemented within our method to make the most of the unprecedented volume of Sentinel-1 data. Finally, a global

405 application of our method would require the simple substitution of a different DEM (ASTER DEM [4], ALOS Global DEM [4]) to estimate the average melting altitude for latitudes above $60 \mathrm{deg}$ North and below $56 \mathrm{deg}$ South which are not covered by SRTM. 


\section{Conclusion}

410

We presented a method to estimate monthly dry and wet SCAs using a combination of MODIS and Sentinel-1 with the GEE platform. We assessed the limitations of the wet snow detection with Sentinel-1, and suggested corrections to mitigate them. The underestimation of wet snow in areas with low fractional snow cover was corrected for by setting all the undetected snow pixels below the average melting altitude as wet snow pixels. This also corrected for undetected wet snow areas because of the limited revisit time of Sentinel-1, compared to the daily MODIS images. Our results also suggest that the detection of wet snow can be related to the fractional cover of wet snow via an exponential model. Finally, a comparison between the monthly change in total SCA and wet SCA highlighted the potential presence of snowmelt processes which occur with a decrease in snow depth but with no/little decrease in snowpack area.

As GEE is designed for planetary-scale analysis, the proposed method could be extended to any areas where Sentinel-1 data are available, allowing routine monitoring of wet and dry SCAs for better understanding of the snowmelt pro${ }_{425}$ cess. Further developments are now needed to enable the assimilation of these Earth Observation measurements in hydrological models for improved management of water resources.

\section{Acknowledgments}

This work was supported by the Natural Environment Research Council (grant number NE/N015541/1) as part of the UK/India research programme, led by NERC and the Ministry of Earth Sciences, on Sustaining Water Resources for Food, Energy \& Ecosystem Services within the Newton-Bhabha Fund.

The research materials supporting this publication can be accessed at the following address http: //catalogue.ceda.ac .uk/uuid/62cc25997f58459581879553f3a25e19.

The authors also would like to thank the SusHi-Wat team for their comments and feedback on the work presented in this paper.

\section{References}

[1] ESA, ESAs Living Planet Programme: Scientific Achievements and Future Challenges. Scientific context of the Earth observation science strategy for ESA, Tech. rep., ESA, SP-1329/2 (2015).

[2] W. W. Immerzeel, L. P. H. Van Beek, M. F. P. Bierkens, Climate change will affect the Asian water towers, Science 328 (5984) (2010) 1382-1385.

[3] P. Singh, S. K. Jain, Snow and glacier melt in the Satluj River at Bhakra Dam in the western Himalayan region, Hydrological Sciences Journal 47 (1) 
[4] S. K. Jain, A. Goswami, A. Saraf, Snowmelt runoff modelling in a himalayan basin with the aid of satellite data, International Journal of Remote Sensing 31 (24) (2010) 6603-6618.

[5] A. W. Nolin, Recent advances in remote sensing of seasonal snow, Journal of Glaciology 56 (200) (2010) 1141-1150.

[6] D. K. Hall, G. A. Riggs, V. V. Salomonson, N. E. DiGirolamo, K. J. Bayr, MODIS snow-cover products, Remote sensing of Environment 83 (1-2) (2002) 181-194.

[7] M. Hori, K. Sugiura, K. Kobayashi, T. Aoki, T. Tanikawa, K. Kuchiki, M. Niwano, H. Enomoto, A 38-year (1978-2015) northern hemisphere daily snow cover extent product derived using consistent objective criteria from satellite-borne optical sensors, Remote sensing of environment 191 (2017) 402-418.

[8] W. G. Rees, Remote sensing of snow and ice, CRC press, 2005.

[9] T. Nagler, H. Rott, E. Ripper, G. Bippus, M. Hetzenecker, Advancements for snowmelt monitoring by means of sentinel-1 sar, Remote Sensing 8 (4) (2016) 348.

[10] T. Schellenberger, B. Ventura, M. Zebisch, C. Notarnicola, Wet snow cover mapping algorithm based on multitemporal COSMO-SkyMed X-band SAR images, IEEE Journal of Selected Topics in Applied Earth Observations and Remote Sensing 5 (3) (2012) 1045-1053.

[11] T. Nagler, H. Rott, Retrieval of wet snow by means of multitemporal sar data, IEEE Transactions on Geoscience and Remote Sensing 38 (2) (2000) $754-765$.

[12] N. Baghdadi, Y. Gauthier, M. Bernier, Capability of multitemporal ERS-1 SAR data for wet-snow mapping, Remote sensing of environment 60 (2) (1997) 174-186.

[13] P. K. Thakur, P. K. Garg, S. P. Aggarwal, R. D. Garg, S. Mani, Snow cover area mapping using synthetic aperture radar in Manali watershed of Beas River in the Northwest Himalayas, Journal of the Indian Society of Remote Sensing 41 (4) (2013) 933-945.

[14] S. Stettner, H. Lantuit, B. Heim, J. Eppler, A. Roth, A. Bartsch, B. Rabus, Terrasar-x time series fill a gap in spaceborne snowmelt monitoring of small arctic catchmentsa case study on qikiqtaruk (herschel island), canada, Remote Sensing 10 (7) (2018) 1155.

[15] E. Malnes, T. Guneriussen, Mapping of snow covered area with Radarsat in Norway, in: Geoscience and Remote Sensing Symposium, 2002. IGARSS'02. 2002 IEEE International, Vol. 1, IEEE, 2002, pp. 683-685. 
[16] N. Longepe, S. Allain, L. Ferro-Famil, E. Pottier, Y. Durand, Snowpack characterization in mountainous regions using C-Band SAR data and a meteorological model, IEEE Transactions on Geoscience and Remote Sensing 47 (2) (2009) 406-418.

[17] G. Rondeau-Genesse, M. Trudel, R. Leconte, Monitoring snow wetness in an Alpine Basin using combined C-band SAR and MODIS data, Remote Sensing of Environment 183 (2016) 304-317.

[18] J. T. Koskinen, J. T. Pulliainen, M. T. Hallikainen, The use of ers-1 sar data in snow melt monitoring, IEEE Transactions on geoscience and remote sensing 35 (3) (1997) 601-610.

[19] S. Pettinato, E. Santi, M. Brogioni, S. Paloscia, P. Pampaloni, An operational algorithm for snow cover mapping in hydrological applications, in: Geoscience and Remote Sensing Symposium, 2009 IEEE International, IGARSS 2009, Vol. 4, IEEE, 2009, pp. IV-964.

[20] T. Nagler, H. Rott, P. Malcher, F. Müller, Assimilation of meteorological and remote sensing data for snowmelt runoff forecasting, Remote sensing of environment 112 (4) (2008) 1408-1420.

[21] R. Solberg, J. Amlien, H. Koren, L. Eikvil, E. Malnes, R. Storvold, Multisensor/multitemporal approaches for snow cover area monitoring, EARSeL LIS-SIG Workshop, Berne.

[22] N. Gorelick, M. Hancher, M. Dixon, S. Ilyushchenko, D. Thau, R. Moore, Google earth engine: Planetary-scale geospatial analysis for everyone, Remote Sensing of Environment 202 (2017) 18-27.

[23] R. Kaushik, J. Shekhar, A. Srivastava, Status paper on rice in Himachal Pradesh, Rice Knowledge Management Portal. Directorate of Rice Research: Rajendranagar, Hyderabad (2011) 1-34.

[24] ESA, Sentinel-1 Toolbox.

URL http://step.esa.int/main/toolboxes/sentinel-1-toolbox/

[25] D. Hall, V. Salomonson, G. Riggs, Modis/terra snow cover daily 13 global $500 \mathrm{~m}$ grid, Boulder, Colorado USA: National Snow and Ice Data Center (Version 5.[Tile h09v04]).

[26] D. K. Hall, G. A. Riggs, Accuracy assessment of the MODIS snow products, Hydrological processes 21 (12) (2007) 1534-1547.

[27] C. Dong, L. Menzel, Improving the accuracy of MODIS 8-day snow products with in situ temperature and precipitation data, Journal of Hydrology 534 (2016) 466-477.

[28] C. Dong, L. Menzel, Producing cloud-free MODIS snow cover products with conditional probability interpolation and meteorological data, Remote Sensing of Environment 186 (2016) 439-451. 
[29] A. Schubert, D. Small, N. Miranda, D. Geudtner, E. Meier, Sentinel-1a product geolocation accuracy: commissioning phase results, Remote sensing 7 (7) (2015) 9431-9449.

[30] N. Baghdadi, C. E. Livingstone, M. Bernier, Airborne C-band SAR measurements of wet snow-covered areas, IEEE transactions on geoscience and remote sensing 36 (6) (1998) 1977-1981.

[31] G. Macelloni, S. Paloscia, P. Pampaloni, F. Marliani, M. Gai, The relationship between the backscattering coefficient and the biomass of narrow and broad leaf crops, IEEE Transactions on Geoscience and Remote Sensing 39 (4) (2001) 873-884.

[32] P. Malcher, T. Nagler, H. Rott, Synergy of sar and optical sensors for snow hydrology application, Proc. of 4th Int. Symposium on Retrieval of Bio-and Geophysical Parameters from SAR Data for Land Applications.

[33] W. W. Immerzeel, N. Wanders, A. Lutz, J. M. Shea, M. F. P. Bierkens, Reconciling high-altitude precipitation in the upper Indus basin with glacier mass balances and runoff, Hydrology and Earth System Sciences 19 (11) (2015) 4673.

[34] T. J. Hegdahl, L. M. Tallaksen, K. Engeland, J. F. Burkhart, C.-Y. Xu, Discharge sensitivity to snowmelt parameterization: a case study for Upper Beas basin in Himachal Pradesh, India, Hydrology Research 47 (4) (2016) 683-700.

[35] M. Konz, D. Finger, C. Buergi, S. Normand, W. Immerzeel, J. Merz, A. Giriraj, P. Burlando, Calibration of a distributed hydrological model for simulations of remote glacierized Himalayan catchments using MODIS snow cover data, in: Global Change: Facing Risks and Threats to Water Resources (Proc. Of the Sixth World FRIEND Conference, Fez, Vol. 340, IAHS Publication, 2010, pp. 465-473.

[36] F. Pellicciotti, C. Buergi, W. W. Immerzeel, M. Konz, A. B. Shrestha, Challenges and uncertainties in hydrological modeling of remote Hindu Kush-Karakoram-Himalayan (HKH) basins: suggestions for calibration strategies, Mountain Research and Development 32 (1) (2012) 39-50.

[37] M. Azmat, F. Laio, D. Poggi, Estimation of water resources availability and mini-hydro productivity in high-altitude scarcely-gauged watershed, Water resources management 29 (14) (2015) 5037-5054.

[38] J. Martinec, Snowmelt-runoff model for stream flow forecasts, Nord. Hydrol. 6 (1975) 145-154.

[39] S. K. Jain, A. Goswami, A. Saraf, Snowmelt runoff modelling in a Himalayan basin with the aid of satellite data, International Journal of Remote Sensing 31 (24) (2010) 6603-6618. 
[40] B. Bookhagen, D. W. Burbank, Toward a complete Himalayan hydrological budget: Spatiotemporal distribution of snowmelt and rainfall and their impact on river discharge, Journal of Geophysical Research: Earth Surface 115 (F3).

[41] H. Wulf, B. Bookhagen, D. Scherler, Differentiating between rain, snow, and glacier contributions to river discharge in the western Himalaya using remote-sensing data and distributed hydrological modeling, Advances in Water Resources 88 (2016) 152-169.

[42] K. T. Senzeba, A. Bhadra, A. Bandyopadhyay, Snowmelt runoff modelling in data scarce Nuranang catchment of eastern Himalayan region, Remote Sensing Applications: Society and Environment 1 (2015) 20-35.

[43] U. K. Haritashya, Effectiveness of Four Water-Bearing Zones of the Glacierized Basin in Meltwater Runoff Modeling, Remote Sensing \& Hydrology 352 .

[44] D. Bocchiola, G. Diolaiuti, A. Soncini, C. Mihalcea, C. D'agata, C. Mayer, A. Lambrecht, R. Rosso, C. Smiraglia, Prediction of future hydrological regimes in poorly gauged high altitude basins: the case study of the upper Indus, Pakistan, Hydrology and Earth System Sciences 15 (7) (2011) 2059.

[45] S. Ragettli, F. Pellicciotti, W. Immerzeel, E. Miles, L. Petersen, M. Heynen, J. Shea, D. Stumm, S. Joshi, A. Shrestha, Unraveling the hydrology of a Himalayan catchment through integration of high resolution in situ data and remote sensing with an advanced simulation model, Advances in Water Resources 78 (2015) 94-111.

[46] A. Soncini, D. Bocchiola, G. Confortola, U. Minora, E. Vuillermoz, F. Salerno, G. Viviano, D. Shrestha, A. Senese, C. Smiraglia, et al., Future hydrological regimes and glacier cover in the Everest region: The case study of the upper Dudh Koshi basin, Science of the Total Environment 565 (2016) 1084-1101.

[47] T. Tachikawa, M. Hato, M. Kaku, A. Iwasaki, Characteristics of ASTER GDEM version 2, in: Geoscience and remote sensing symposium (IGARSS), 2011 IEEE international, IEEE, 2011, pp. 3657-3660.

[48] T. Tadono, H. Ishida, F. Oda, S. Naito, K. Minakawa, H. Iwamoto, Precise global DEM generation by ALOS PRISM, ISPRS Annals of the Photogrammetry, Remote Sensing and Spatial Information Sciences 2 (4) (2014) 71. 